\title{
Novel compound heterozygous mutations in low density lipoprotein receptor gene causes a severe phenotype in a Chinese hypercholesterolemia family
}

\author{
XINYAO CHENG $^{1 *}$, YIFANG HUANG $^{2 *}$, XUEPING QIU ${ }^{2}$, XIAOHUAN CHENG ${ }^{2}$,

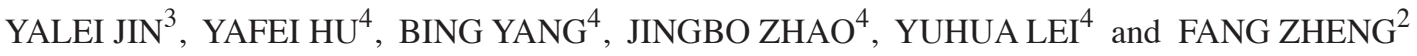 \\ ${ }^{1}$ Cardiovascular Division; ${ }^{2}$ Center for Gene Diagnosis; ${ }^{3}$ Geriatrics Division, Zhongnan Hospital, Wuhan University, \\ Wuhan, Hubei 430071; ${ }^{4}$ Ultrasonography Division, Enshi Center Hospital, Enshi, Hubei 445000, P.R. China
}

Received October 9, 2015; Accepted February 7, 2017

DOI: $10.3892 /$ etm.2018.6205

\begin{abstract}
Mutations in the low density lipoprotein receptor $(L D L R)$ gene serve a causative role in the pathophysiology of familial hypercholesterolemia ( $\mathrm{FH})$, a common autosomal inherited disorder characterized by abnormal lipid metabolism. The aim of the present study was to investigate genetic defects in a Chinese family with FH. Clinical features and family histories were collected, as were the results of various laboratory tests, including determinations of serum lipid concentrations, ultrasonography and angiography results. Potential mutations in $L D L R$ were screened using direct polymerase chain reaction (PCR) sequencing. Multiple sequence alignments, structure and hydrophobicity predictions were performed in silico. Novel compound heterozygote mutations in $L D L R$ of the proband were identified, with a Trp577Term-bearing maternal allele and a Pro685Leu-bearing paternal allele. The proband, a 27-year-old male, had severe and diffuse coronary stenosis and non-ST segment elevation myocardial infarction, as well as multiple skin xanthomas and high serum lipid levels. The allele-dosage-dependent clinical features, including hypercholesterolemia and peripheral arterial atherosclerosis, were observed in the proband and the other heterozygous patients.
\end{abstract}

Correspondence to: Professor Fang Zheng, Center for Gene Diagnosis, Zhongnan Hospital, Wuhan University, 169 Donghu Road, Wuchang, Wuhan, Hubei 430071, P.R. China

E-mail: zhengfang@whu.edu.cn

${ }^{*}$ Contributed equally

Abbreviations: FH, familial hypercholesterolemia; LDLR, low density lipoprotein receptor; PCR, polymerase chain reaction; heFH, heterozygous $\mathrm{FH}$; hoFH, homozygous $\mathrm{FH}$; APOB, apolipoprotein B; LDL-C, LDL cholesterol; GLU, blood glucose; TC, total cholesterol; HDL-C, high-density lipoprotein cholesterol; EKG, electrocardiogram

Key words: coronary artery disease familial hypercholesterolemia, $L D L R$ gene, atherosclerosis, xanthomas,
Therefore, the coexistence of Pro685Leu and Trp577Term mutations in $L D L R$ is a novel compound heterozygosis in Chinese patients and may lead to a severe FH phenotype. The explanation for the existence of compound heterozygous mutations instead of homozygous mutations in this particular family requires further study.

\section{Introduction}

Familial hypercholesterolemia (FH) is an inherited genetic disease characterized by hyperlipidemia, skin xanthomas on extensor tendons and/or corneal arcus, and early onset of all forms of atherosclerotic diseases including premature death secondary to lifelong pathogenic elevations of serum cholesterol (1). FH exhibits an autosomal dominant transmission pattern with $\geq 90 \%$ penetrance (1). It is typically divided into two main phenotypes: Heterozygous FH (heFH) and homozygous $\mathrm{FH}$ (hoFH). hoFH is less common than heFH and patients with hoFH often exhibit more severe symptomatic phenotypes with higher levels of serum cholesterol (2).

It has been reported that mutations in more than 3 genes, including low density lipoprotein receptor ( $L D L R)$, apolipoprotein B-100 (APOB), proprotein convertase subtilisin/kexin type 9 and LDL receptor adaptor protein 1 , are involved in the pathogenesis of FH (3-6). Notably, LDLR mutations account for $85-90 \%$ of $\mathrm{FH}$ cases and $>1,700$ variants of $L D L R$ have been identified $(7,8)$. The human $L D L R$ gene encodes an 860 -amino-acid protein that serves a significant role in the uptake and degradation of LDL by the LDLR pathway (9). An in vivo study by Anderson indicated that mutations in the LDLR gene could cause dysfunction of the LDLR protein, leading to the destruction of the LDLR pathway in vivo, resulting in elevated serum cholesterol levels and premature coronary artery disease (10).

It has previously been reported that the incidence of $L D L R$ mutations is $\sim 70 \%$ in Chinese patients with FH. However, these patients remain largely unidentified, particularly in rural areas, due to patients and clinicians having little knowledge about this disease and limited access to genetic testing (11-13). A few cases of FH in China have been diagnosed based primarily on clinical symptoms, but the phenotype of $\mathrm{FH}$ 
is highly variable (3). Different gene mutations and dosage effects of modifier genes may lead to discrepancies in clinical manifestations and responses to drugs (14-16). It is therefore important to investigate the association between $\mathrm{FH}$ genotype and phenotype. In the present study, a novel compound heterozygosis was identified by direct polymerase chain reaction (PCR) sequencing of LDLR. Laboratory tests and bioinformatics analysis were also conducted to investigate the possible role of this mutation.

\section{Subjects and methods}

Study subjects. A total of 10 individuals from a Chinese FH family were enrolled in the present study from December 2014 to May 2015 at Zhongnan Hospital of Wuhan University (Wuhan, China), including 4 males and 6 females, with an age range of 2-76 years (Fig. 1 and Table I). All individuals enrolled in our study were members of this FH family and consented to genetic and clinical examinations. Individuals in the family who refused examinations were excluded. The family history and basic physical information of subjects were collected. The present study was approved by the Ethics Committee of Zhongnan Hospital of Wuhan University. Prior informed consent was obtained from all subjects, including the parents of participants $<16$ years old. The young male proband (III1, 27-year-old) was the offspring of a consanguineous marriage (II1 and II2), as the grandfather of II1 and the grandmother of II 2 were siblings.

Clinical examinations and biochemical tests. Blood samples were harvested following overnight fasting. Serum was separated by centrifugation at 2,200 $\mathrm{x} g$ at $4^{\circ} \mathrm{C}$ and examined using an automatic biochemical analyzer (Abbot-AEROSET; Abbott Diagnostics, Santa Clara, CA, USA) for a series of biochemical indices in the clinical laboratory department of Zhongnan Hospital of Wuhan University: Blood glucose (GLU), total cholesterol (TC), LDL-C, high-density lipoprotein cholesterol (HDL-C), triglycerides, apolipoprotein (APO) A, APOB, lipoprotein a and C-reactive protein.

All participants received ultrasonography and electrocardiogram (EKG) examinations. A coronary contrast angiography was performed on the proband using the digital subtract angiographic system (Phillip Corp. FD 20; Phillips Healthcare, DA Best, The Netherlands). The number and severity of peripheral artery atherosclerotic plaques (PAS) of each individual was evaluated.

Genetic analysis. Genomic DNA was extracted from $1 \mathrm{ml}$ peripheral blood of all subjects using the sodium dodecyl sulfate-proteinase $\mathrm{K}$ method as previously described (17). DNA quality was assessed using a NanoDrop 2000c spectrophotometer (NanoDrop; Thermo Fisher Scientific, Inc., Waltham, MA, USA). All exons of $L D L R$ were screened for mutations using PCR direct sequencing as previously described $(18,19)$. Amplifications were performed in a Hema 9600 PCR thermocycler (Hema Medical Instrument Co. Ltd, Zhuhai, China) with a total volume of $25 \mu 1$, including 1x Taq DNA Polymerase (Thermo Fisher Scientific, Inc.), 1x Taq Buffer, $0.5 \mu \mathrm{M}$ of forward and reverse primers (Table II) and 100 ng DNA template. The conditions of PCR amplification were $95^{\circ} \mathrm{C}$ for $30 \mathrm{sec}$ for denaturation, annealing temperature (Table II) for $45 \mathrm{sec}$ for annealing, $72^{\circ} \mathrm{C}$ for $45 \mathrm{sec}$ for extension ( 38 cycles of amplification). PCR products were evaluated by $2 \%$ agarose gel electrophoresis, purified by an Axygen ${ }^{\circledR}$ PCR Clean-Up Kit (Axygen Biosciences, Inc.; Corning Incorporated, Corning, NY, USA) and directly sequenced using an ABI Genetic Analyzer 3730xl (Applied Biosystems; Thermo Fisher Scientific, Inc.).

Multiple Sequence Alignments and prediction of LDLR mutations. The alignment of LDLR protein sequences in multiple species (obtained from the National Center for Biotechnology Information protein database, www.ncbi.nlm.nih.gov/protein) was performed using ClustalX2 software (Wellcome Trust Genome Campus, Hinxton, UK). The secondary structure and hydrophobicity of the mutant LDLR protein were predicted using ANTHEPROT 5.0 (PRABI-Lyon-Gerland, Lyon, France), and three-dimensional (3D) structure prediction was carried out using Swiss-Pdb Viewer 4.01 (Swiss Institute of Bioinformatics, Lausanne, Switzerland) (20-22).

\section{Results}

FH pedigree. The young male proband (III1, 27-year-old) was the offspring of a consanguineous marriage (II1 and II2), as the grandfather of II1 and the grandmother of II2 were siblings (Fig. 1). The proband was first diagnosed with hypercholesterolemia in May 2015 when a biochemical test was taken, due to aggravated angina. The proband presented with multiple skin xanthomas (Fig. 2A) of various sizes on his extensor tendons in the fingers, elbows, knees and Achilles. Notably, these xanthomas first appeared when he was 10 years old. Arcus corneas, white rings in the corneal margin, an indicator of lipid deposits, were found bilaterally (Fig. 2A). The proband frequently experienced (four times per day for two years) paroxysmal chest discomfort and pain of several minutes duration each time, with accompanying palpitations and breathlessness, which were heavier during physical exertion. The proband's father (II2) died as a result of lung cancer at the age of 33 and also had skin xanthomas according to descriptions by other family members. The proband's brother (III2, 22-year-old) exhibited moderate symptoms of partial xanthoma and sporadic angina. Abnormal symptoms did not manifest in other family members.

Results of clinical examinations and biochemical tests. The blood lipid levels of the subjects were shown in Table I. The proband exhibited elevated levels of TC $(18.30 \mathrm{mmol} / \mathrm{l})$, LDL-C (11.60 mmol/l) and APOB (3.81 g/l) compared with the normal range; the proband's mother, brother and aunt, heterozygous in this study, also had high TC (8.10-9.40 mmol/l), LDL-C (4.86-5.02 mmol/l) and APOB (1.65-1.86 g/l) levels (Table I). The rest of the subjects were found to have levels of TC, LDL-C and APOB within normal ranges (Table I). Furthermore, HDL-C level in the proband $(0.60 \mathrm{mmol} / \mathrm{l})$ was lower than the normal range, whereas it was within the normal range for all other subjects. These data are consistent with the diagnostic criteria for $\mathrm{FH}$ (23).

Clinical features and examination results are listed in Table III. For the proband, precordial auscultation revealed a 
Table I. The serum lipid levels of the subjects.

\begin{tabular}{|c|c|c|c|c|c|c|c|c|c|c|c|}
\hline Subjects & Sex & $\begin{array}{l}\text { Age, } \\
\text { years }\end{array}$ & $\begin{array}{c}\mathrm{TC} \\
\mathrm{mmol} / \mathrm{l}\end{array}$ & $\begin{array}{c}\text { TG } \\
\mathrm{mmol} / 1\end{array}$ & $\begin{array}{c}\text { HDL-C } \\
\mathrm{mmol} / \mathrm{l}\end{array}$ & $\begin{array}{l}\text { LDL-C } \\
\mathrm{mmol} / \mathrm{l}\end{array}$ & $\begin{array}{c}\text { APOA } \\
\mathrm{g} / 1\end{array}$ & $\begin{array}{c}\text { APOB } \\
\mathrm{g} / 1\end{array}$ & $\begin{array}{c}\mathrm{LPa} \\
\mathrm{g} / 1\end{array}$ & $\begin{array}{l}\text { CRP } \\
\mathrm{mg} / \mathrm{l}\end{array}$ & $\begin{array}{c}\text { GLU } \\
\mathrm{mmol} / 1\end{array}$ \\
\hline $\begin{array}{l}\text { Normal } \\
\text { range }\end{array}$ & 1 & 1 & $2.8-5.8$ & $0.45-1.81$ & $0.9-2$ & $2.1-3.3$ & $1.05-1.75$ & $0.6-1.4$ & $0-0.3$ & $0-8$ & $3.8-6.1$ \\
\hline $\mathrm{I}^{\mathrm{a}}$ & $\mathrm{M}$ & 76 & 4.50 & 0.81 & 1.08 & 2.14 & 1.52 & 0.85 & 0.14 & $<0.5$ & 3.90 \\
\hline III $1^{\mathrm{a}}$ & $\mathrm{F}$ & 52 & 8.10 & 1.14 & 1.04 & 5.02 & 1.37 & 1.72 & 0.48 & $<0.5$ & 4.30 \\
\hline II5 & $\mathrm{F}$ & 48 & 5.10 & 0.75 & 1.45 & 2.38 & 1.89 & 0.89 & 0.09 & $<0.5$ & 3.90 \\
\hline $\mathrm{II}^{\mathrm{a}}$ & $\mathrm{F}$ & 45 & 9.40 & 1.53 & 1.65 & 4.93 & 2.17 & 1.86 & 0.52 & $<0.5$ & 3.90 \\
\hline IIII $1^{\text {a }}$ & $\mathrm{M}$ & 27 & 18.30 & 2.67 & 0.60 & 11.60 & 1.11 & 3.81 & 0.14 & $<0.5$ & 3.50 \\
\hline III $2^{\mathrm{a}}$ & $\mathrm{M}$ & 22 & 8.20 & 0.92 & 1.05 & 4.86 & 1.46 & 1.65 & 0.06 & 6.46 & 4.50 \\
\hline III3 & $\mathrm{F}$ & 22 & 3.90 & 0.61 & 1.34 & 1.61 & 1.77 & 0.61 & 0.13 & $<0.5$ & 4.00 \\
\hline III4 & $\mathrm{F}$ & 27 & 4.50 & 0.33 & 1.58 & 1.84 & 1.85 & 0.66 & 0.27 & $<0.5$ & 4.00 \\
\hline III6 & $\mathrm{F}$ & 22 & 3.90 & 0.74 & 1.13 & 1.69 & 1.64 & 0.68 & 0.48 & $<0.5$ & 3.90 \\
\hline IV1 & $\mathrm{M}$ & 2 & 3.50 & 1.13 & 0.95 & 1.57 & 1.40 & 0.55 & 0.21 & $<0.5$ & 5.00 \\
\hline
\end{tabular}

Subjects marked with an aharbor a causative mutation. TC, total cholesterol; TG, triglyceride; HDL-C, high density lipoprotein; LDL-C, low density lipoprotein; APOA, apoprotein A; APOB, apoprotein B; Lpa, lipoprotein a; CRP, C reaction protein; GLU, glucose; M, male; F, female.

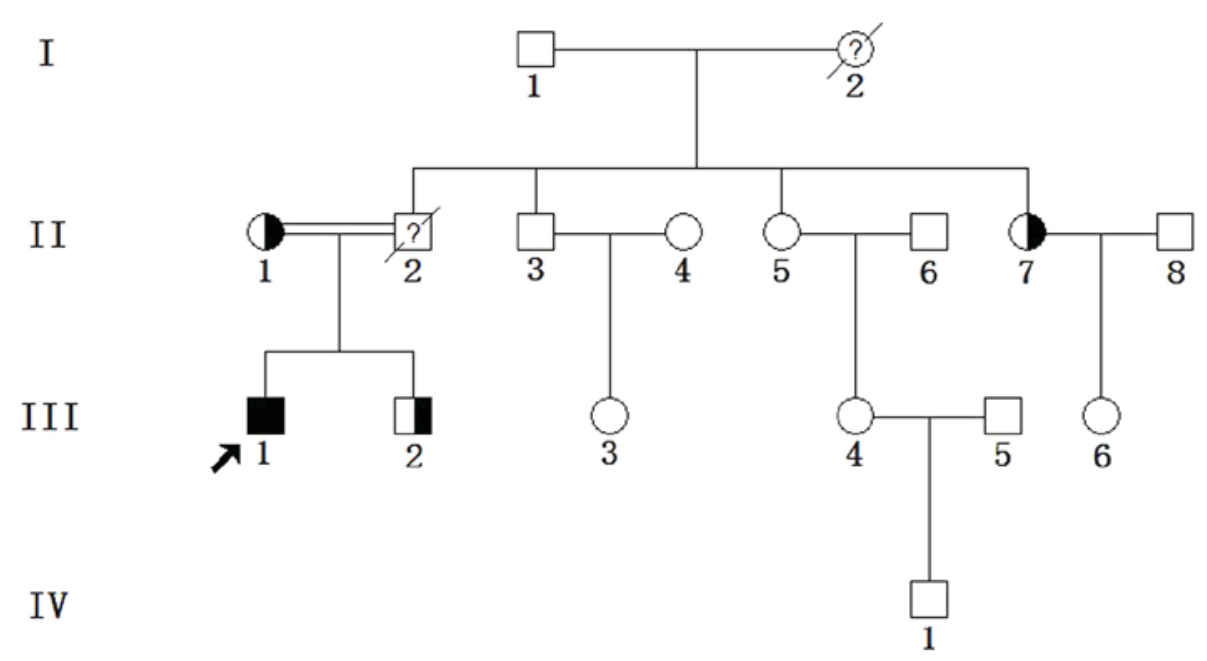

Figure 1. Pedigree chart for the familial hypercholesterolemia family in the present study. Black symbols indicate affected members who carry the Trp577Term or Pro685Leu mutation. Half black half white symbols indicate members heterozygous for $L D L R$ mutation, fully black symbols indicate members homozygous for $L D L R$ mutation, and fully white symbols indicate members without $L D L R$ mutation. '?' indicate members with an unknown genotype. 'I', 'II', 'III' and 'IV' indicate the generations of this family. Squares indicate males, circles indicate females.

3-4/6 grade systolic murmur at the area of aortic valve. EKG found that the ST segment depressed in V4, V5 and V6 leads reaching to $0.5 \mathrm{mv}$. Angiography revealed diffuse and heavy coronary artery stenosis. The left main coronary trunk and the anterior descending branch narrowed at $80 \%$ and the proximal circumflex branch at $50 \%$; the right coronary narrowed in the proximal segment at $85 \%$, the middle at $85 \%$, and the distal at $70 \%$ (Fig. 2C). Ultrasonography revealed that the aortic valve was calcified with mild stenosis and regurgitation, the mitral valve had mild regurgitation, and there was extensive and heavy peripheral arterial atherosclerosis (Fig. 2B). By contrast, other family members presented only subtle abnormalities or normal manifestations. Subjects with unique heterozygote mutations presented with mild abnormalities. Ultrasonography revealed fewer plaques (II1, II7, III2) and no cardiac structural malformation and dysfunction, and the EKGs found mild ST segment depression (II1) or normal state. The healthy members with no causative mutations (II5, III3, III4, III6, IV1) had normal cardiac and peripheral arterial results, with the exception of the proband's grandfather (I1) who had aortic valve calcification and mild regurgitation as well as inferior $\mathrm{Q}$ wave in the EKG. It was concluded that these characteristics were most likely due to age (Table III). Numerous peripheral artery atherosclerotic plaques were observed in the proband, and five, two and three plaques were observed in the proband's mother, brother and aunt, respectively. However, atherosclerotic plaques were not observed in non-FH members.

Trp557Term and Pro685Leu mutations in LDLR gene. The results from the genetic analysis are presented in Table III. 
Table II. Primers for the $L D L R$ gene.

\begin{tabular}{|c|c|c|c|c|}
\hline Exon & Forward primer $\left(5^{\prime} \rightarrow 3^{\prime}\right)$ & Reverse primer $\left(5^{\prime} \rightarrow 3^{\prime}\right)$ & $\begin{array}{l}\text { Amplicon } \\
\text { length (bp) }\end{array}$ & $\begin{array}{c}\text { Annealing } \\
\text { temperature }\left({ }^{\circ} \mathrm{C}\right)\end{array}$ \\
\hline $\begin{array}{l}5 \text { ' near } \\
\text { gene-Exon1 }\end{array}$ & CTTCACCGGAGACCCAAATA & TTCCCTTAAATCCCTCAGACTC & 592 & 58 \\
\hline Exon2 & CAGACTGTTCCTGATCGGATG & AAGGGGTTAAGAATCGTGTCAC & 422 & 60 \\
\hline Exon3 & TGGGTCTTTCCTTTGAGTGAC & TAGCACCATCCCCACTTTGT & 366 & 58 \\
\hline Exon4 & TAGAATGGGCTGGTGTTGGG & TACTTTCTTGGCATGTTGTTGG & 567 & 60 \\
\hline Exon5 & AAGTAAGGTGGCACGATTATG & AGCAGCAAGGCACAGAGAAT & 470 & 62 \\
\hline Exon6 & AAGCAAACTGAGGCTCAGACAC & TGGAGTTCCCAAAACCCTACAG & 272 & 62 \\
\hline Exon7 & TGTAATGAGCCAAGGTTGGC & GTTTGGTTGCCATGTCAGGAA & 261 & 58 \\
\hline Exon8 & GCTGTTTCCTTGATTACATCTC & GATATGAGTCTGTGCAAAGTTC & 367 & 60 \\
\hline $\begin{array}{l}\text { Exon9- } \\
\text { Exon10 }\end{array}$ & CTTGGTTCCATCGACGGGTC & CATGCCCAGCCCACTAACCA & 626 & 62 \\
\hline Exon11 & GGTTCCCAGCAGGACTATTTC & GAAAGAGGGAAACCTTCAGG & 358 & 60 \\
\hline Exon12 & TGACCTCTCCTTATCCACTTGT & CTCCTAGTCACAACCAGTTTTC & 272 & 60 \\
\hline $\begin{array}{l}\text { Exon13- } \\
\text { Exon14 }\end{array}$ & GAGGGTGGCCTGTGTCTCAT & ATGAGTCCTTACAACGACCTTG & 605 & 60 \\
\hline Exon15 & GTCATTTGAGACTTTCGTCATTAG & AAGAGGGCAAGAACTGTTATTAGAC & 457 & 60 \\
\hline Exon16 & CTGCCTGCTCCATTTCTTGG & СТССАСАТССТССАТСТGАСС & 349 & 60 \\
\hline $\begin{array}{l}\text { Exon17 } \\
\text { Exon18- }\end{array}$ & TCAAGGTTATGGTACGATGCC & TTGCCCTGTCACCATCTGAT & 485 & 62 \\
\hline 3' near gene & TTTCCTGAATGCTGGACTGAT & GAGAAACTCAAAACTTCCTGGAG & 360 & 60 \\
\hline
\end{tabular}

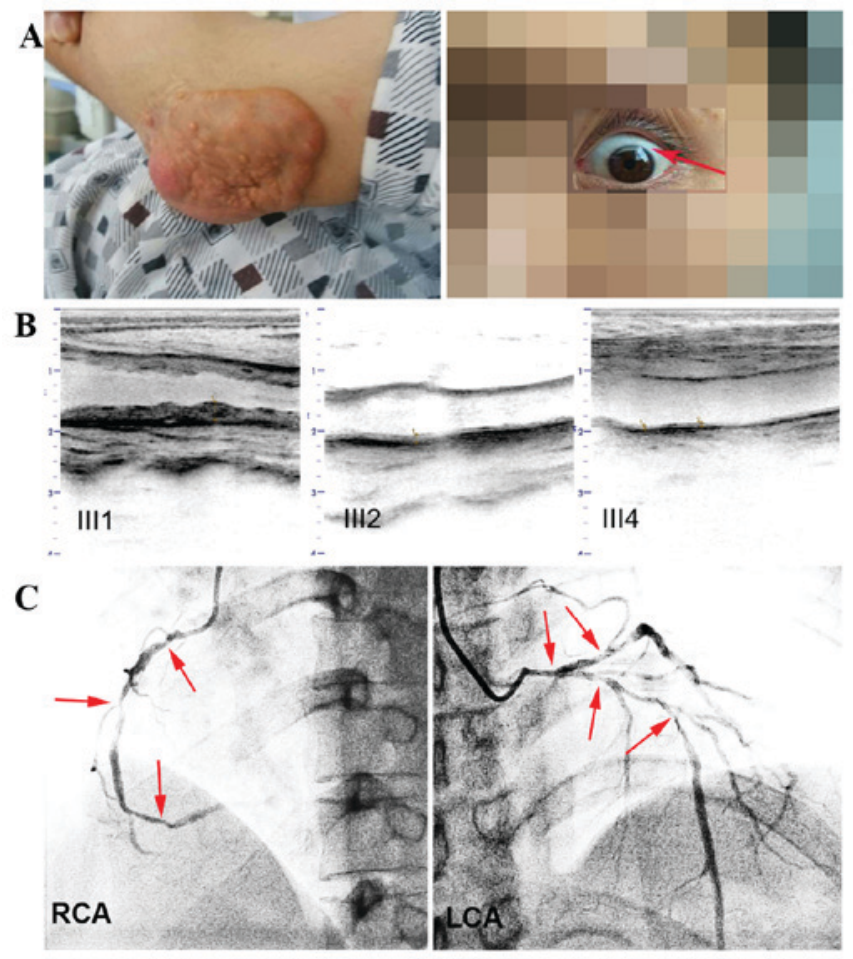

Figure 2. Clinical characteristics of III1 and photographic, ultrasonography results. (A) Elbow tendon xanthomata and the corneal arcus, which is a shadow-like white curve on the upper edge of the cornea. (B) Comparison of the distal carotid segment atherosclerosis between patients III1, III2 and III4. (C) Coronary angiogram from III1. Arrows indicate multiple stenosis of the RCA and LCA. IIII, the proband. RCA, right coronary artery; LCA, left coronary artery. III1, the proband, the compound heFH subject. III2, the proband's brother, an heFH subject. III4, the proband's cousin, an unaffected subject.
Compound heterozygote mutations (Trp577Term and Pro685Leu) in $L D L R$ were identified in the proband (Fig. 3A and B). The proband's mother (II1) and brother (III2) were heterozygous for the Trp577Term mutation and his aunt (II7) was heterozygous for the Pro685Leu mutation.

Multiple sequence alignments and prediction of LDLR mutations. Multiple sequence alignments revealed that these two amino acid alterations (Trp577Term and Pro685Leu) were located in the highly conserved region of $L D L R$ in different species (Fig. 3C). The 3D ribbon model in silico prediction identified an obvious truncation in mutant LDLR protein caused by the Trp577Term mutation, which may lead to haplo-insufficiency (Fig. 4A and B). The secondary structure prediction revealed that the Pro685Leu mutant LDLR appeared to have more $\beta$-strands in its secondary structure than the wild type (Fig. 4C and D). Furthermore, the hydrophobicity of the Pro685Leu mutant protein was altered at the corresponding mutant region (Fig. 4E and F). Combined, these variations in the physicochemical properties of LDLR may be responsible for its functional abnormality.

\section{Discussion}

$L D L R$ mutations are known to cause FH. In the present study, two novel compound heterozygous $L D L R$ mutations, Trp577Term and Pro685Leu, were identified in the proband of a Chinese FH family. Furthermore, one of these two mutations was detected in the proband's mother, brother and aunt. According to pedigree analysis (Fig. 1), the Pro685Leu mutation was paternally inherited, whereas the Trp577Term 
Table III. The clinical and molecular data of all subjects.

\begin{tabular}{|c|c|c|c|c|c|c|c|}
\hline \multirow[b]{2}{*}{ Subjects } & \multirow[b]{2}{*}{ Angina } & \multirow[b]{2}{*}{ Xanthoma } & \multicolumn{2}{|c|}{ Mutation } & \multirow[b]{2}{*}{ EKG } & \multirow[b]{2}{*}{ PAS } & \multirow[b]{2}{*}{ EchoCG } \\
\hline & & & cDNA & Amino acid & & & \\
\hline $\mathrm{I}^{\mathrm{a}}$ & - & - & $1773 \mathrm{C}>\mathrm{T} ; 1959 \mathrm{~T}>\mathrm{C}$ & Asn591Asn; Val653Val & Inferior Q & 3 & AVC/AR \\
\hline $\mathrm{II} 1^{\mathrm{b}}$ & - & - & $1731 \mathrm{G}>\mathrm{A}$ & Trp577Term & STd & 5 & - \\
\hline II5 & - & - & - & - & STd & - & - \\
\hline $\mathrm{II}^{\mathrm{b}}$ & - & - & $2054 \mathrm{C}>\mathrm{T}$ & Pro685Leu & Normal & 3 & - \\
\hline IIII $1^{b, c}$ & + & + & $1731 \mathrm{G}>\mathrm{A} ; 2054 \mathrm{C}>\mathrm{T}$ & Trp577Term;Pro685Leu & STd heavy & Numerous & AVC/AS/AR/MR \\
\hline $\mathrm{III} 2^{\mathrm{b}}$ & - & + & $1731 \mathrm{G}>\mathrm{A}$ & Trp577Term & Normal & 2 & - \\
\hline III3 & - & - & - & - & Normal & - & - \\
\hline III4 & - & - & $1773 \mathrm{C}>\mathrm{T} ; 1959 \mathrm{~T}>\mathrm{C}$ & Asn591Asn; Val653Val & Normal & - & - \\
\hline III6 & - & - & - & - & Normal & - & - \\
\hline IV1 & - & - & - & - & Normal & - & - \\
\hline
\end{tabular}

Subjects marked with ${ }^{a}$ smoke 1 pack/day for 9 years, ${ }^{b}$ suffer from a causative mutation and ${ }^{\mathrm{c}}$ smoke 1-2 pack/day for 30 years. PAS, number of peripheral artery atherosclerotic plaques, referred as to IMT>1.5 mm or 50\% neighbor thickness; EchoCG, echocardiography; Q, electrocardiographic Q wave; STd, ST segment depressed; AVC, aortic valvular calcification; AR, aortic valvular regurgitation; AS, aortic valvular stenosis; MR, mitral regurgitation.

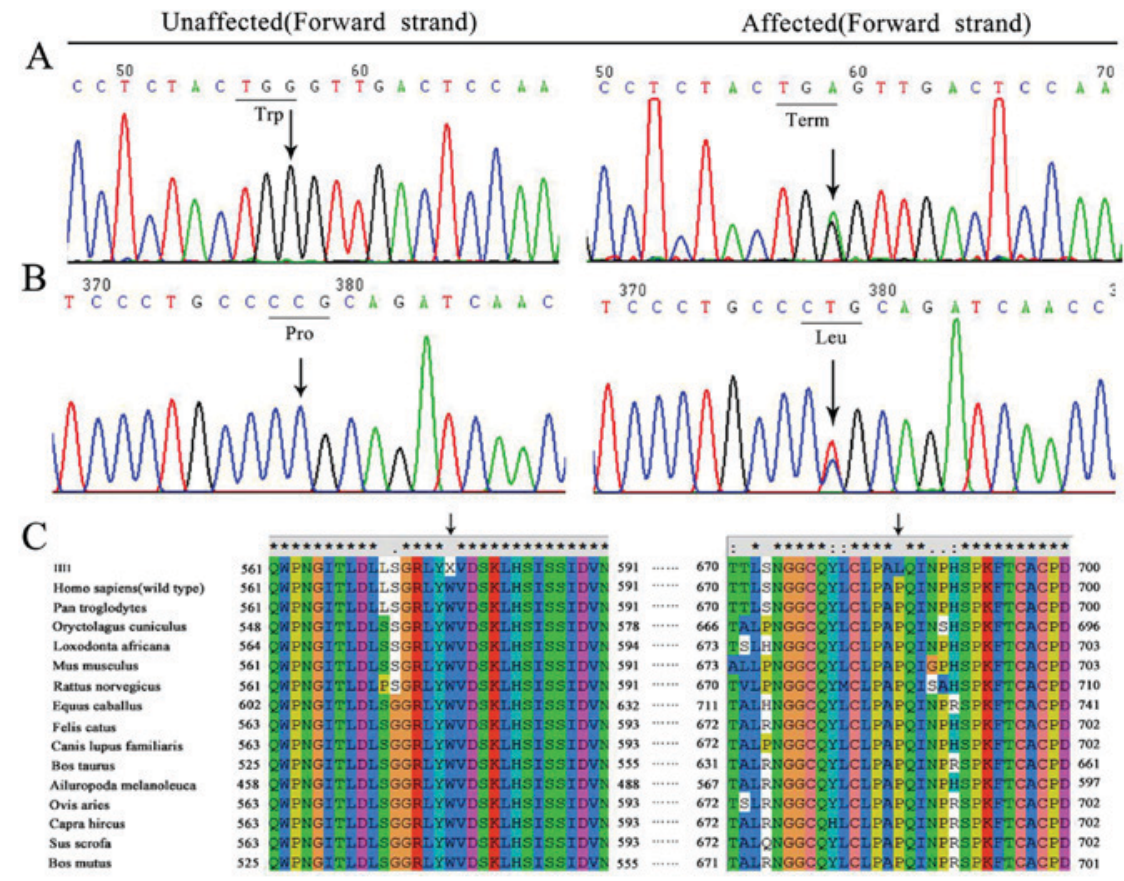

Figure 3. Sequencing results of the $L D L R$ mutations and alignment of multiple LDLR protein sequences. (A) The sequence chromatogram of a wild-type allele with tryptophan (TGG) at codon 577, and the mutant allele with a heterozygous mutation of Trp577Term (c.1731G>A) in affected members. (B) The sequence chromatogram of a wild-type allele with proline (CCG) at codon 685, and the mutant allele with a heterozygous mutation of Pro685Leu (c.2054C $>\mathrm{T}$ ) in affected members. (C) Multiple sequence alignments revealed that these two missense mutations affected amino acids located in the highly conserved amino acid region in different species. LDLR, low density lipoprotein receptor.

was maternally inherited. In this particular family, all mutation carriers were found to have elevated serum lipid levels, typical atherosclerotic plaques and coronary artery stenosis, all of which are indicators of early onset atherosclerosis. Notably, these symptoms were more severe in the compound heterozygote proband, suggesting that the LDLR mutation has a possible dosage effect in lipid metabolism. It was observed that the serum level of HDL-C was decreased in the proband and within the normal range for other family members, which suggests that elevated LDL-C may be responsible for low HDL-C levels, resulting in a vicious cycle effect in the proband. The proband also presented with bilateral corneal arcus and non-ST segment elevation myocardial infarction, and only he and his brother presented skin xanthomas. This indicates a sex-biased phenotype (II1 vs. III2). There was little difference observed in the phenotypes of two female suffers 


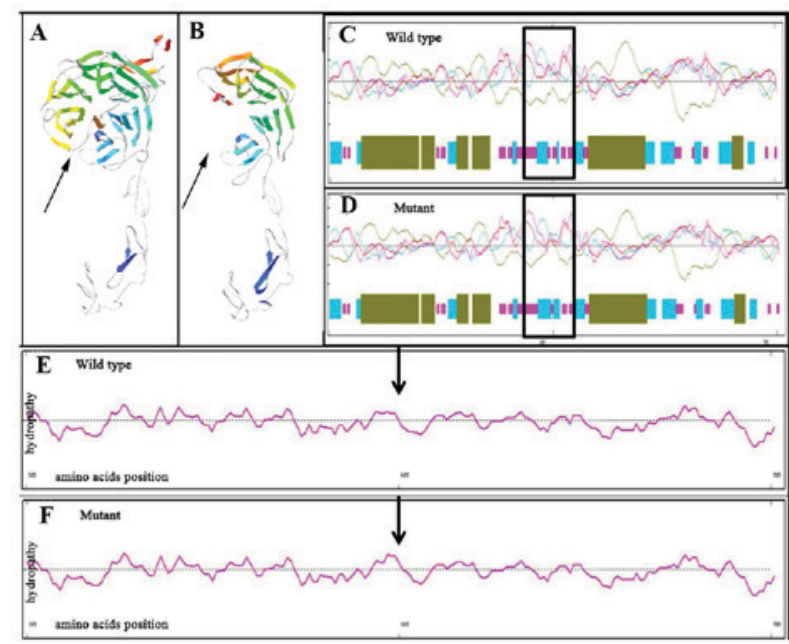

Figure 4. In silico predictions for LDLR mutations. The ribbon protein models of (A) wild-type and (B) Trp577Term mutant forms are displayed. The mutant protein exhibits an abnormally reduced amino acid chain. The predicted secondary structures of (C) the wild-type form and (D) the Pro685Leu mutant form. Black boxes indicate the mutated section. Hydropathy plot of (E) wild-type and (F) Pro685Leu mutant forms. Black arrows indicate the region of mutant site. LDLR, low density lipoprotein receptor.

(II1 and II7), which suggests that the two mutations have a comparable effect in FH. There was a step-wise severity in clinical symptoms from hoFH, heFH to unaffected subjects, including xanthoma, sporadic angina, hypercholesterolemia and peripheral artery atherosclerotic plaques and stenosis. These results suggest a genetic dosage-dependent clinical feature of $\mathrm{FH}$.

The Trp577Term mutation is located in exon 12. The typical outcome of this type of mutation is premature termination of transcription, leading to a truncated protein lacking EGF, O-linked sugars, membrane spanning and cytoplasmic structure domains $(9,24)$. The Pro685Leu mutation is located in exon 14 , which is the highly conserved region of the EGF precursor domain in the LDLR protein (25). Previous studies have demonstrated that this alteration affects the flexibility of the LDLR polypeptide chain and the rigidity of the peptide bonds adjacent to proline $(26,27)$.

Based on previous reports, each of the Trp577Term and Pro685Leu mutations in LDLR can cause FH independently $(26,28)$. The Trp577Term mutation has only been documented in Chinese patients, and to the best of our knowledge, the compound heterozygous mutations have not been reported elsewhere. The present study indicated that compound heterozygous mutations resulted in a severe clinical manifestation of FH.

In the present study, the proband's parents were third degree relatives. It is well known that parents who both have common heterozygous mutations in a consanguineous marriage tend to give birth to homozygous children; however, in the present study the proband was a compound heterozygote instead. It is therefore worth studying the underlying association between incestuous family histories and the incidence of heterozygous mutations. Two missense mutations of Asn591Asn (c.1773C > T) and Val653Val (c.1959T>C) were also identified in this family, which are also able to increase LDL-C levels $(29,30)$. However, the subjects carrying one or both of these variations in the present study had normal levels of TC and LDL-C. Since the study population of the above two studies were Canadians and Japanese, respectively, we speculate that the different outcome of these variations in our study may be influenced by the difference of environmental or ethnic factors.

There were certain limitations in the present study that must be considered. In the present study, the mechanism of destruction effects of Trp577Term and Pro685Leu mutations were only analyzed using bioinformatics tools. Further biological studies are required to confirm the underlying mechanism on mutant protein functions. Investigations involving more families and more mutation carriers will be helpful for the prevention and early intervention for Chinese $\mathrm{FH}$ populations.

\section{Acknowledgements}

The authors of the present study would like to thank the proband and his family for participating in this study, and Enshi Center Hospital of China for their assistance.

\section{References}

1. Hopkins PN, Toth PP,Ballantyne CM and Rader DJ; National Lipid Association Expert Panel on Familial Hypercholesterolemia: Familial hypercholesterolemias: Prevalence, genetics, diagnosis and screening recommendations from the National Lipid Association Expert Panel on Familial Hypercholesterolemia. J Clin Lipidol 5(3 Suppl): S9-S17, 2011.

2. Raal FJ and Santos RD: Homozygous familial hypercholesterolemia: Current perspectives on diagnosis and treatment. Atherosclerosis 223: 262-268, 2012.

3. van der Graaf A, Avis HJ, Kusters DM, Vissers MN, Hutten BA, Defesche JC, Huijgen R, Fouchier SW, Wijburg FA, Kastelein JJ and Wiegman A: Molecular basis of autosomal dominant hypercholesterolemia: Assessment in a large cohort of hypercholesterolemic children. Circulation 123: 1167-1173, 2011.

4. Tada H, Kawashiri MA, Ohtani R, Noguchi T, Nakanishi C, Konno T, Hayashi K, Nohara A, Inazu A, Kobayashi J, et al: A novel type of familial hypercholesterolemia: Double heterozygous mutations in LDL receptor and LDL receptor adaptor protein 1 gene. Atherosclerosis 219: 663-666, 2011.

5. Mabuchi H, Nohara A, Noguchi T, Kobayashi J, Kawashiri MA, Inoue T, Mori M, Tada H, Nakanishi C, Yagi K, et al: Genotypic and phenotypic features in homozygous familial hypercholesterolemia caused by proprotein convertase subtilisin/kexin type 9 (PCSK9) gain-of-function mutation. Atherosclerosis 236: 54-61, 2014.

6. Rader DJ, Cohen J and Hobbs HH: Monogenic hypercholesterolemia: New insights in pathogenesis and treatment. J Clin Invest 111: 1795-1803, 2003.

7. Goldberg AC, Hopkins PN, Toth PP, Ballantyne CM, Rader DJ, Robinson JG, Daniels SR, Gidding SS, de Ferranti SD, Ito MK, et al: Familial hypercholesterolemia: Screening, diagnosis and management of pediatric and adult patients: Clinical guidance from the National Lipid Association Expert Panel on Familial Hypercholesterolemia. J Clin Lipidol 5 (3 Suppl): S1-S8, 2011.

8. University College London (UCL): LDLR FH database. http://www. ucl.ac.uk/ldlr/Current/index.php?select_db=LDLR. Accessed September 14, 2015.

9. Soutar AK and Naoumova RP: Mechanisms of disease: Genetic causes of familial hypercholesterolemia. Nat Clin Pract Cardiovasc Med 4: 214-225, 2007.

10. Anderson RG: Joe Goldstein and Mike Brown: From cholesterol homeostasis to new paradigms in membrane biology. Trends Cell Biol 13: 534-539, 2003.

11. Mak YT, Pang CP, Tomlinson B, Zhang J, Chan YS, Mak TW and Masarei JR: Mutations in the low-density lipoprotein receptor gene in Chinese familial hypercholesterolemia patients. Arterioscler Thromb Vasc Biol 18: 1600-1605, 1998.

12. Shi Z, Yuan B, Zhao D, Taylor AW, Lin J and Watts GF: Familial hypercholesterolemia in China: Prevalence and evidence of underdetection and undertreatment in a community population. Int J Cardiol 174: 834-836, 2014. 
13. Fan LL, Lin MJ, Chen YQ, Huang H, Peng DQ, Xia K, Zhao SP and Xiang R: Novel mutations of low-density lipoprotein receptor gene in china patients with familial hypercholesterolemia. Appl Biochem Biotechnol 176: 101-109, 2015.

14. Desaphy JF, Gramegna G, Altamura C, Dinardo MM, Imbrici P, George AL Jr, Modoni A, Lomonaco M and Conte Camerino D: Functional characterization of ClC-1 mutations from patients affected by recessive myotonia congenita presenting with different clinical phenotypes. Exp Neurol 248: $530-540,2013$.

15. Moosa MM, Ayub MI, Bashar AE, Sarwardi G, Khan W, Khan H and Yeasmin S: Combination of two rare mutations causes $\beta$-thalassaemia in a Bangladeshi patient. Genet Mol Biol 34 406-409, 2011

16. Kasana BA, Dar WR, Aziz SA, Lone AR, Sofi NU, Dar IA, Latief M, Arshad F, Hussain M and Hussain M: Epidermal growth factor receptor mutation in adenocarcinoma lung in a North Indian population: Prevalence and relation with different clinical variables. Indian J Med Paediatr Oncol 37: 189-195, 2016.

17. Loparev VN, Cartas MA, Monken CE, Velpandi A and Srinivasan A: An efficient and simple method of DNA extraction from whole blood and cell lines to identify infectious agents. J Virol Methods 34: 105-112, 1991.

18. Cheng $X$, Ding J, Zheng F, Zhou $X$ and Xiong C: Two mutations in LDLR gene were found in two Chinese families with familial hypercholesterolemia. Mol Biol Rep 36: 2053-2057, 2008.

19. Li H, Zhang Y, Wei X, Peng Y, Yang P, Tan H, Chen C, Pan Q, Liang D and Wu L: Rare intracranial cholesterol deposition and a homozygous mutation of LDLR in a familial hypercholesterolemia patient. Gene 569: 313-317, 2015.

20. Mothobi ME, Guo S, Liu Y, Chen Q, Yussuf AS, Zhu X and Fang Z: Mutation analysis of congenital cataract in a Basotho family identified a new missense allele in CRYBB2. Mol Vis 15 $1470-1475,2009$.
21. Chen Q, Ma J, Yan M, Mothobi ME, Liu Y and Zheng F: A novel mutation in CRYAB associated with autosomal dominant congenital nuclear cataract in a Chinese family. Mol Vis 15: 1359-1365, 2009.

22. Yan M, Xiong C, Ye SQ, Chen Y, Ke M, Zheng F and Zhou X: A novel connexin 50 (GJA8) mutation in a Chinese family with a dominant congenital pulverulent nuclear cataract. Mol Vis 14 : 418-424, 2008

23. Hovingh GK, Davidson MH, Kastelein JJ and O'Connor AM: Diagnosis and treatment of familial hypercholesterolaemia. Eur Heart J 34: 962-971, 2013.

24. Goldstein JL and Brown MS: The LDL receptor. Arterioscler Thromb Vasc Biol 29: 431-438, 2009.

25. Davis CG, Goldstein JL, Südhof TC, Anderson RG, Russell DW and Brown MS: Acid-dependent ligand dissociation and recycling of LDL receptor mediated by growth factor homology region. Nature 326: 760-765, 1987.

26. Yao RE, Wang J, Geng J, Zheng Z, Yu T, Yu Y and Fu Q: Identification of LDLR mutations in two Chinese pedigrees with familial hypercholesterolemia. J Pediatr Endocrinol Metab 25: 769-773, 2012.

27. Sun XM, Patel DD, Webb JC, Knight BL, Fan LM, Cai HJ and Soutar AK: Familial hypercholesterolemia in China. Identification of mutations in the LDL-receptor gene that result in a receptor-negative phenotype. Arterioscler Thromb 14: 85-94, 1994

28. Hobbs HH, Brown MS and Goldstein JL: Molecular genetics of the LDL receptor gene in familial hypercholesterolemia. Hum Mutat 1: 445-466, 1992.

29. Boright AP, Connelly PW, Brunt JH, Morgan K and Hegele RA: Association and linkage of LDLR gene variation with variation in plasma low density lipoprotein cholesterol. J Hum Genet 43: 153-159, 1998

30. Yamada Y, Ichihara S, Kato K, Yoshida T, Yokoi K, Matsuo H, Watanabe S, Metoki N, Yoshida H, Satoh K, et al: Genetic risk for metabolic syndrome: Examination of candidate gene polymorphisms related to lipid metabolism in Japanese people. J Med Genet 45: 22-28, 2008. 